pubs.acs.org/acsaelm

\title{
High-Temperature Specific Contact Resistance of Iron Disilicide Soldered to Molybdenum by Field's Metal
}

\author{
Antoine Micallef,* Christian Stiewe,* Gregor Oppitz, and Eckhard Müller
}

Cite This: https://dx.doi.org/10.1021/acsaelm.0c01020

Read Online
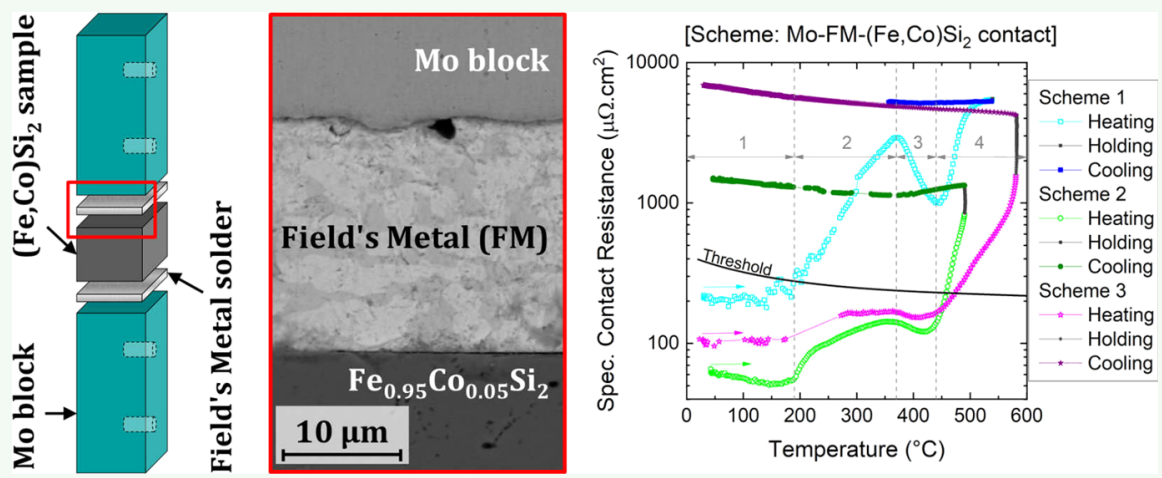

ABSTRACT: The target of this study is to evaluate the suitability of a contact scheme designed for thermoelectric characterization of $\mathrm{FeSi}_{2}$-based materials with the combined thermoelectric measurement (CTEM) technique. A Fe ${ }_{0.95} \mathrm{Co}_{0.05} \mathrm{Si}_{2}$ sample is mounted between the CTEM sample holder blocks made of molybdenum using Field's metal solder. The electrical contact resistance is monitored under thermal cycling up to $580{ }^{\circ} \mathrm{C}$ by an in-house built contact resistance in situ monitoring facility. After cycling, the microstructure was studied by scanning electron microscopy and energy-dispersive X-ray spectroscopy on the cross section of the contact zone. For the developed preparation process, the specific contact resistance was found suitably low up to $415^{\circ} \mathrm{C}(<200 \mu \Omega$. $\mathrm{cm}^{2}$ which is less than $10 \%$ of the sample resistance). Above $415^{\circ} \mathrm{C}$, oxidation degrades the electrical contact irreversibly.

KEYWORDS: specific contact resistance, surface oxidation, liquid solder, high-temperature measurement, thermoelectric material, characterization

\section{INTRODUCTION}

Sustainable energies will play a key role in the energy production of the future. Thermoelectrics (TEs) can help, by improving the efficiency of energy intensive processes through heat waste recovery. Based on a solid-state phenomenon, the Seebeck effect, TE materials can convert a heat flow into electricity, and the opposite through the Peltier effect. With the significant demand of highly efficient TE materials, functional characterization represents a crucial step in their development. The efficiency of a TE material is quantified through the dimensionless figure of merit $(z T)$ which is defined by its Seebeck coefficient $(S)$, electrical conductivity $(\sigma)$, and thermal conductivity $(\kappa)$, with $T$ being the absolute temperature

$$
z T=\frac{S^{2} \sigma}{\kappa} T
$$

To facilitate TE material development, a combined thermoelectric measurement (CTEM) facility is being designed to simultaneously determine the above properties as well as the material's $z T_{\mathrm{H}}$ by using the Harman method, up to $600{ }^{\circ} \mathrm{C}$.
Simultaneous measurements save time, reduce measurement errors, and make comparison of properties more reliable. For high measurement accuracy, high-quality contacts between the sample and metal blocks are necessary. Besides lateral homogeneity, low thermal and electrical contact resistances and the applied joining technique should allow for simple sample removal after the measurement, for further use of the (preferably unaffected) sample and holder blocks. Progressing reactions and strong diffusion have to be avoided, and the contacts between the sample and the blocks need to remain stable up to the maximum desired temperature of measurement, over the duration of one or a few measurement cycles (with a duration of typically $10-20 \mathrm{~h}$ per cycle).

Received: November 19, 2020

Accepted: January 21, 2021 

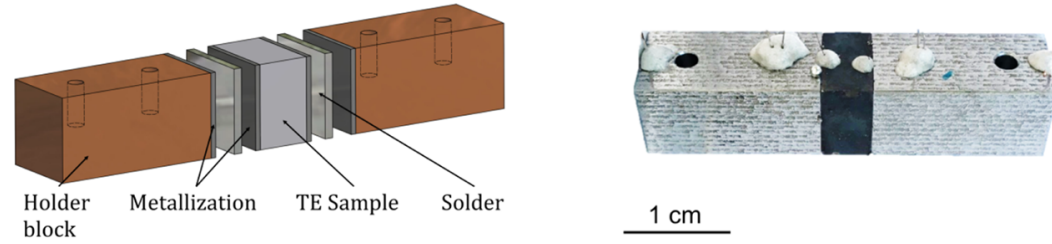

$1 \mathrm{~cm}$

Figure 1. Sample holder of the CTEM. Left: Exploded view of the assembly presents the different layers of the contact scheme. Both holes on the top side of the blocks are used for wiring. Right: Photograph with wiring fixed by ceramic paste.
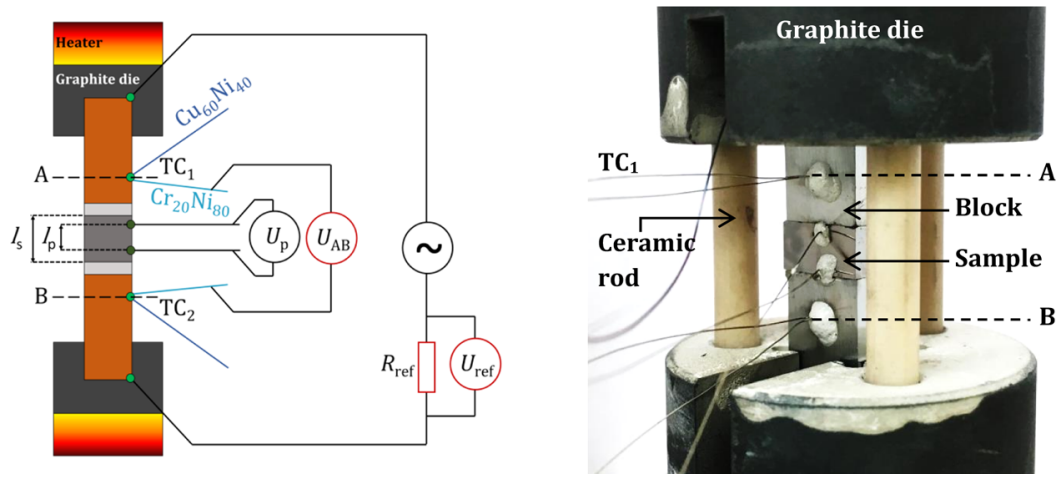

Figure 2. Left: schematic of the setup and wiring of the CoRIS monitoring facility. Right: sample holder placed in the graphite die between the heaters.

The measurement principle was suggested decades ago by Ioffe $^{2}$ and improved by Stecker and Teubner ${ }^{3}$ for usage below or near room temperature. ${ }^{4}$ More recently, Kolb et al. demonstrated that the CTEM is able to measure reliably up to $330{ }^{\circ} \mathrm{C}$ using Galinstan solder ${ }^{5}$ to join a Skutterudite sample to $\mathrm{Cr}$ coated $\mathrm{Cu}$ blocks. ${ }^{1}$ Above $330{ }^{\circ} \mathrm{C}$, the gallium of the solder reacted with the sample and the blocks, preventing measurement at higher temperature. Low-melting solders, to connect a sample between two brackets of copper, are likewise required for impedance spectroscopy on TE samples. ${ }^{6,7}$ Garcia-Canadas et al. faced degrading reactions at the joints above $250{ }^{\circ} \mathrm{C}$. More and more high-temperature applications are developed for $\mathrm{TE}$ materials, many of them extending up to $600{ }^{\circ} \mathrm{C}$, meaning we need reliable characterization methods for their development.

For this reason, the temperature limits of CTEM contacts should be raised. This study is focused on a contact development for n-type iron disilicide which is connected to molybdenum holder blocks by a Bi-In-Sn solder. The assembly was thermally cycled under vacuum, and the electrical contact was monitored. After heat treatment, the contact zone was studied by electron microscopy.

\section{CONTACTING SETUP}

In the CTEM sample holder, a TE sample is installed between two metal blocks of equal shape and weight (Figure 1), which have a much higher thermal and electrical conductivity compared to a usual TE semiconductor sample. In our experiment, the metal blocks are $16 \mathrm{~mm}$ long and match the sample's cross section to ensure a homogeneous temperature field and electrical field along the sample during measurement. If required by the sample's chemistry and the temperature range of measurement, protective coatings can be applied to the contact surfaces of the sample or the metal blocks in order to prevent undesired chemical reactions with the solder. The metallization can be necessary to suppress diffusion of atoms from the blocks or solder into the sample which could change its properties. The layering of the materials, which compose the CTEM sample holder, is named as the contact scheme (Figure 1). Such a contact scheme has to be developed for each material class, while the solder material itself has to be selected appropriately with respect to its compatibility to the block and sample materials. In this study, sample and holder metal blocks are connected at their base faces by a low melting $\left(T_{\mathrm{m}}=62{ }^{\circ} \mathrm{C}\right)$ solder named Field's metal (FM) based on bismuth, indium, and tin. The measurement at elevated temperature is thus performed, while the solder is in a liquid state.

\section{MATERIALS}

$\mathrm{N}$-type cobalt-doped TE iron disilicide, $\mathrm{Fe}_{0.95} \mathrm{Co}_{0.05} \mathrm{Si}_{2}$, is known as a standard reference material for the Seebeck coefficient measurement. ${ }^{8,9}$ Good contacts between the $(\mathrm{Fe}, \mathrm{Co}) \mathrm{Si}_{2}$ sample and holder blocks are required to enable the referencing of the CTEM method to a satisfactory standard. The alloy $\mathrm{Fe}_{0.95} \mathrm{Co}_{0.05} \mathrm{Si}_{2}$ was synthesized as a powder by gas atomization by the company H.C. Starck (Goslar, Germany). Elemental analysis provided by the supplier certified the phase composition $\left(\mathrm{Fe}_{0.95} \mathrm{Co}_{0.05} \mathrm{Si}_{2}\right)$ but revealed also a small amount of oxygen $(0.05$ at. \% O ). The introduction of oxygen in the system can significantly influence the TE properties of the material. ${ }^{10}$ However, the same powder and synthesis were used in the certification process of the Co-doped $\mathrm{FeSi}_{2}$ as standard reference materials for Seebeck coefficient measurement, ${ }^{9}$ resulting in the same TE properties. This confirms the very high reproducibility of the applied preparation route. The iron disilicide samples were hot-pressed from the received powder at 1050 ${ }^{\circ} \mathrm{C}$ under an axial pressure of $54 \mathrm{MPa}$ in vacuum $\left(10^{-3} \mathrm{mbar}\right)$ for 30 min. Subsequently, the samples were annealed for $24 \mathrm{~h}$ at $850^{\circ} \mathrm{C}$ to form the semiconducting $\beta$-phase. Chen et al. studied the dynamic phase transformation of $\mathrm{FeSi}_{2}$ and in detail, the systematic $\beta$-phase formation with respect to heating rate, Co-content, and applied pressure. ${ }^{11}$ Samples were cut into $8 \times 8 \times(4-5) \mathrm{mm}^{3}$ square prism shape for the contacting experiments. The density of the obtained samples was measured with the buoyancy method at $4.77 \mathrm{~g} \cdot \mathrm{cm}^{-3}$ which corresponds to $97.3 \%$ of the theoretical density.

The alloy $\mathrm{Bi}_{32.5} \mathrm{In}_{51} \mathrm{Sn}_{16.5}$ (FM, ${ }^{12,13}$ supplied by Rotometals, San Leandro, USA) was used as a joining solder between the metal blocks and the TE sample. Its low melting temperature allows the sample to be easily soldered to and unsoldered from the metal blocks on a hot plate under air. Preliminary high-temperature diffusion experiments between FM and the other components of the scheme combined with the 
Table 1. Overview of the Three Contact Schemes under Investigation

\begin{tabular}{|c|c|c|c|}
\hline schemes & 1 & 2 & 3 \\
\hline blocks & fresh Mo blocks & Mo blocks of scheme 1 & fresh Mo blocks \\
\hline solder & fresh FM & fresh FM & fresh FM \\
\hline sample & fresh $\mathrm{FeSi}_{2}$ sample & $\mathrm{FeSi}_{2}$ sample of scheme 1 & fresh $\mathrm{FeSi}_{2}$ sample \\
\hline $\begin{array}{c}\text { contact surfaces } \\
\text { pre-treatment }\end{array}$ & $\begin{array}{l}\text { cleaned with ethanol before } \\
\text { assembly }\end{array}$ & $\begin{array}{l}\text { grinded with } 4000 \mathrm{SiC} \text { paper and cleaned with } \\
\text { ethanol }\end{array}$ & $\begin{array}{l}\text { grinded with } 4000 \mathrm{SiC} \text { paper and cleaned with } \\
\text { ethanol }\end{array}$ \\
\hline maximum temperature & $540{ }^{\circ} \mathrm{C}$ & $490{ }^{\circ} \mathrm{C}$ & $580^{\circ} \mathrm{C}$ \\
\hline
\end{tabular}

consultation of available phase diagrams, both indicated that no damaging reactions were expected below $600{ }^{\circ} \mathrm{C} .{ }^{14-16}$

The choice of the block material might also be restricted due to its compatibility requirement with the sample and solder materials. When the CTEM method was introduced decades ago, it was referring to $\mathrm{Ni}$ plated $\mathrm{Cu}$ blocks to measure bismuth telluride-based solid solutions below room temperature. ${ }^{17}$ However, molybdenum was selected for the measurement at elevated temperature, which likewise owns a high electrical and thermal conductivity $\left(\sigma=1.75 \times 10^{5} \mathrm{~S} \cdot \mathrm{cm}^{-1} ; \kappa=138 \mathrm{~W}\right.$. $\left.\mathrm{m}^{-1} \cdot \mathrm{K}^{-1}\right)$ and does not react with $\mathrm{FM}$ elements below $600{ }^{\circ} \mathrm{C}$.

In the schemes studied in this manuscript, no metallization was applied neither to the sample nor to the holder blocks.

\section{CONTACTING METHOD}

For contact preparation, solder is pre-applied on the contact areas of both the blocks and the sample. These are heated on a hot plate under air at a temperature slightly above the solder's melting point. A molybdenum tip is used to gently spread the solder on the overall contact surface to assist wetting of the solder to the surface. No contamination related to the tip material was observed in the tested schemes; however, traces of oxygen might have been introduced. Subsequently, the blocks and the sample are pre-assembled on the hot plate. The assembly is cooled and forms a compact structure with established contacts. The blocks and sample are then wired with type E thermocouples, and current leads (see Figure 2) by laser welding (LSW 4002 Baasel Lasertech). Wiring connections are secured against breakoff using a high-temperature resistant ceramic paste (CC high temp cement) purchased from OMEGA (Figure 1).

\section{SPECIFIC CONTACT RESISTANCE MEASUREMENT}

A custom-made facility named "contact resistance in situ" (CoRIS) monitoring facility was built to evaluate the temperature dependence of the electrical contact resistance and to monitor its evolution under thermal cycling. The sandwich of metal blocks and TE sample is vertically wedged between two graphite dies aligned by ceramic rods (Figure 2) and connected to resistive heaters at the top and bottom. Thermocouples and signal leads attached to the metal blocks and the TE sample (see Figure 2 right) by laser welding allow for temperature and resistance reading during the measurement, which can be performed up to $600{ }^{\circ} \mathrm{C}$ under high vacuum $\left(\approx 10^{-4} \mathrm{mbar}\right)$. Wiring connections are applied, as indicated in Figure 2, in order to monitor the electrical resistance by a 4-point measurement which eliminates the probes' wire and contact resistance.

Temperatures and resistance are measured continuously during the temperature cycle which consists of a temperature ramp up, holding period at max temperature and a cooling phase. Heating rate and holding time can be adjusted by a process control software. Cooling proceeds either passively or is ramped down at a slow rate. Temperatures are measured in both blocks by thermocouples $\left(\mathrm{TC}_{1}\right.$ and $\mathrm{TC}_{2}$ ) and are averaged to estimate the sample temperature.
To measure the sample resistance, an AC current of about 90 $\mathrm{mA}$ with a frequency of $121.21 \mathrm{~Hz}$ is used. The frequency was chosen high enough to prevent undesired spurious thermovoltages due to the Peltier effect. As the sample resistance is typically in the milliohm range, the measured voltages are around a few microvolts; therefore, lock-in amplifiers are used to suppress noise. The sample current $(I)$ is precisely determined over a reference resistance $\left(R_{\text {ref }}\right)$ by a voltage measurement $\left(U_{\text {ref }}\right)$. The sample resistance $\left(R_{\mathrm{s}}\right)$ and the resistance between positions $\mathrm{A}$ and $\mathrm{B}$ at the blocks $\left(R_{\mathrm{AB}}\right)$ are simultaneously measured with a 4-point measurement each (see Figure 2).

$$
R_{\mathrm{AB}}=U_{\mathrm{AB}} / I \text {, with } I=U_{\text {ref }} / R_{\text {ref }}
$$

Assuming a symmetric setup, the total resistance $\left(R_{\mathrm{AB}}\right)$ comprises three contributions: twice the block resistance $\left(R_{\text {block}}\right)$, twice the contact resistance $\left(R_{\mathrm{c}}\right)$, and once the sample resistance $\left(R_{\mathrm{s}}\right)$.

$$
R_{\mathrm{AB}}=2 R_{\text {block }}+2 R_{\mathrm{c}}+R_{\mathrm{s}}
$$

The experiment conditions require the blocks to be suitably conductive, at least two orders of magnitude higher than the sample, so that the blocks' resistance can be neglected practically. The sample resistance is measured either in situ with additional probes fixed on the sample, or separately, in advance, by another in-house-built measurement facility for electrical conductivity. With that, the contact resistance can be expressed as

$$
R_{\mathrm{c}}=\frac{R_{\mathrm{AB}}-R_{\mathrm{s}}}{2}, \text { with } R_{\mathrm{s}}=\frac{1}{\sigma_{\mathrm{s}}} \cdot \frac{l_{\mathrm{s}}}{A} \text { or } R_{\mathrm{s}}=\frac{l_{\mathrm{s}}}{l_{\mathrm{p}}} \cdot \frac{U_{\mathrm{p}}}{I}
$$

To eliminate geometry, the specific contact resistance $\left(\rho_{\mathrm{c}}\right)$ is calculated taking into account the contact area $\left(A_{c}\right)$.

$$
\rho_{\mathrm{c}}=R_{\mathrm{c}} \cdot A_{\mathrm{c}}
$$

Specific contact resistance measurements have been performed between room temperature and $580{ }^{\circ} \mathrm{C}$. The heating ramp was consistently set to $2 \mathrm{~h}$ from room temperature to top temperature, a holding time period of $1 \mathrm{~h}$, followed by a passive cooling, which lasted roughly $8 \mathrm{~h}$.

To analyze the microstructure of the contact regions after measurement, the contact cross section of the setup at the envelope face was grinded to remove a surface layer of several micrometers in thickness and was polished. The contact area was scanned using scanning electron microscopy (SEM), and elemental analysis was performed by energy-dispersive X-ray spectroscopy (EDX) in order to reveal reaction layers and/or diffusion processes.

\section{RESULTS AND DISCUSSION}

Three different contact schemes have been studied. They are all comprising the same material sequence. The contact constituents are sometimes reused from one scheme to another. The contact surface pre-treatment varies as well as the maximum 
temperature of the temperature cycles. These variations, as detailed in Table 1, exert an impact on the electrical contact properties.

The evolution of the specific contact resistance over the first temperature cycle on schemes 1, 2, and 3 is shown in Figure 3.

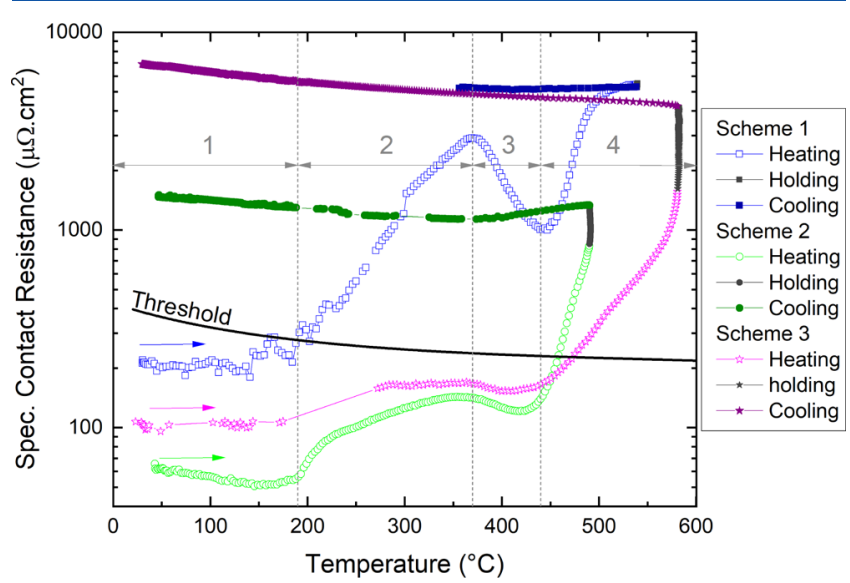

Figure 3. Contact resistance measurements on schemes 1, 2, and 3. Four distinct temperature phases characterize the evolution of the specific contact resistance during the heating period. An accuracy threshold for the CTEM measurement suitability is represented by the black curve, benchmarked at $10 \%$ of a typical sample resistance.

The heating curves of the three schemes present a qualitatively similar behavior and can be split into four phases. Phase 1 corresponds to a plateau up to $190^{\circ} \mathrm{C}$. From 190 to $370{ }^{\circ} \mathrm{C}$, in phase 2 , the contact resistance increases. In phase 3 , the contact resistance gradually decreases from 370 to $420-440{ }^{\circ} \mathrm{C}$, depending on the scheme. In phase 4 , the heating curves show a steep contact resistance increase, which by far exceeds the threshold set at $10 \%$ of a typical sample resistance. During the holding period, the schemes behave differently-scheme 1 stabilizes above $500{ }^{\circ} \mathrm{C}$ at a higher specific resistance than both of the other schemes which continuously increase during the holding period.

The variation in the resistance measurements (Figure 3) between the three schemes can most likely be attributed to the different pre-treatments of the contact surfaces and to different maximum measurement temperatures. Nevertheless, the temperature trends and onset temperatures of the specific phases are similar. It can be assumed that the different pre-treatments lead to varying oxygen content in the solder and on the contact surfaces causing this disparity. Indeed, for scheme 1, blocks and sample contact surfaces were grinded several days before assembling, allowing oxygen to adhere to the surfaces. For the schemes 2 and 3, assembly was performed right after blocks and sample contact surfaces were grinded and cleaned, most likely leaving the schemes with the reduced oxygen content at the contact locations. In addition, a less pronounced temperature dependence of the electrical resistance was observed in the heating phase (see Figure 3).

Iron disilicide materials are known to quickly form a thin silica layer when exposed to air which protects the inner sample from oxidation. ${ }^{18}$ The anti-oxidation layer is non-conductive and provides high contact resistance when the solder is melted between the contact surfaces. The pre-soldering method, explained in the Contacting Method section, consists of abrading or removing the silica layer to allow for direct contact between solder and sample. The developed joining technique establishes a suitable electrical contact, with a starting value of the contact resistance measured below the threshold for all schemes (Figure 3). The melting point of the solder at $62{ }^{\circ} \mathrm{C}$ does not show any effect on the contact resistance values, which means that the contact does not change during melting of the solder. Hence, wetting does not worsen at this point and obviously the solder resistance itself does not substantially contribute to the measured resistance.

In phase 2 , the specific contact resistance starts to increase with different scheme-specific slopes, giving evidence of progressing contact degradation. The trend is inversed in phase 3 , although the decrease of the contact resistance up to $(420 ; 440){ }^{\circ} \mathrm{C}$ is more pronounced for scheme 1 . For all schemes, the decrease is comparably strong as the increase in the previous phase, which could be understood as a partial reversal of the same process. The peak between phases 2 and 3 can be related to a surface energy inversion phenomenon between the liquid solder and remaining oxygen, which will be explained below.

The quality of the interfaces relies on the wetting interrelation between the contact surfaces and the liquid FM. The stronger the wetting degree of the liquid solder is to the substrate material, the more stable is the metallic bond between them. The degree of wetting of a liquid solder on a substrate is expressed by the contact angle $\theta$ between the solder and the substrate in the liquid. The contact angle is related to the surface energy by Young's equation which interconnects the surface energy of the liquid solder $\sigma_{\mathrm{lv}}$, the surface energy of the solid substrate $\sigma_{\mathrm{sv}}$, and the interfacial tension between the solid substrate and the liquid solder $\sigma_{\text {sl }}($ see eq 6$)$.

$$
\cos (\theta)=\frac{\sigma_{\mathrm{sv}}-\sigma_{\mathrm{sl}}}{\sigma_{\mathrm{lv}}}
$$

For good wetting, $\theta$ must be as small as possible which means that $\sigma_{\mathrm{lv}}$ must be kept as small as possible. A thin oxide layer on the liquid solder and substrate is harmful for the wetting of the substrate as it reduces the surface energy of the substrate and also prevents intimate contact between the solder and substrate. For information, $\sigma_{\mathrm{lv}}$ and the surface tension $\gamma_{\mathrm{lv}}$ are equal for liquids and have equivalent units. ${ }^{19}$

Ricci et al. ${ }^{20,21}$ studied the oxygen influence on the surface tension of several liquid metals, including indium and tin, under reduced pressure and with a low and constant oxygen vapor pressure. In the FM, indium element rules the solder oxidation since the indium oxide $\operatorname{In}_{2} \mathrm{O}_{3}$ has the lower formation energy compared to the ones of tin and bismuth oxides. ${ }^{22}$ Therefore, the study of the indium-oxygen system ${ }^{23}$ is the most relevant for this study. Higher temperatures, above the indium melting point, stimulate the oxygen adsorption on the liquid surface ${ }^{24}$ which leads to the growth of the oxide $\mathrm{In}_{2} \mathrm{O}_{3}$. The surface tension of liquid indium is increasing with temperature because of the oxide formation on its surface. According to Ricci, the surface tension trend of the liquid indium is inversed at $370{ }^{\circ} \mathrm{C}$ and starts to decrease with increasing temperature. This behavior is induced by the decomposition of the $\operatorname{In}_{2} \mathrm{O}_{3}$ into the volatile species $\operatorname{In}_{2} \mathrm{O}$. Another publication reported that a $\mathrm{In}_{2} \mathrm{O}_{3}$ thin film on the liquid indium surface was dissociated by the reaction: $\mathrm{In}_{2} \mathrm{O}_{3(\mathrm{c})}+4 \mathrm{In}_{(\mathrm{l})}=3 \mathrm{In}_{2} \mathrm{O}_{(\mathrm{g})}$ from $360{ }^{\circ} \mathrm{C}$ in a vacuum below $10^{-9}$ mbar. $^{25}$ The surface tension of indium influences the contact resistance of our systems because of a change in surface wetting by the solder. An inversion point in the contact resistances' temperature trends is also observed in the heating curves at $370^{\circ} \mathrm{C}$, as shown in Figure 3 . 
We assume that the vacuum chamber of the CoRIS facility contains residual oxygen despite a vacuum of about $10^{-4}$ mbar. In addition, oxygen is adsorbed on parts of the contacting schemes during the pre-assembly step performed under air around $90{ }^{\circ} \mathrm{C}$. At $190{ }^{\circ} \mathrm{C}$, the oxide layer formation is accelerated on the liquid solder's surface. ${ }^{26,27}$ This interaction increases the surface energy, ${ }^{23}$ hence degrades the wetting between solder and contact surfaces, leading to an increase in the contact resistance. When the $\mathrm{In}-\mathrm{O}$ inversion point $\left(370{ }^{\circ} \mathrm{C}\right)$ is reached, the oxide layer thickness of the liquid's surface decreases due to the decomposition of $\operatorname{~nn}_{2} \mathrm{O}_{3}$ into volatile oxides, reducing the solder surface energy. Consequently, the surface wetting is improved, causing the electrical resistance curves to decrease right above $370{ }^{\circ} \mathrm{C}$. The grinding step for schemes 2 and 3 reduces surface roughness and the content of trapped oxygen in the scheme; therefore, the imprint of the variation of the surface energy of the solder onto the contact resistance is considerably mitigated.

The observed resistance increase above $415{ }^{\circ} \mathrm{C}$ seems to be induced by an oxidation of the sample. Indeed, oxygen-rich phases were regularly detected close to the sample contact surface, as presented in the micrographs of Figure 4. The

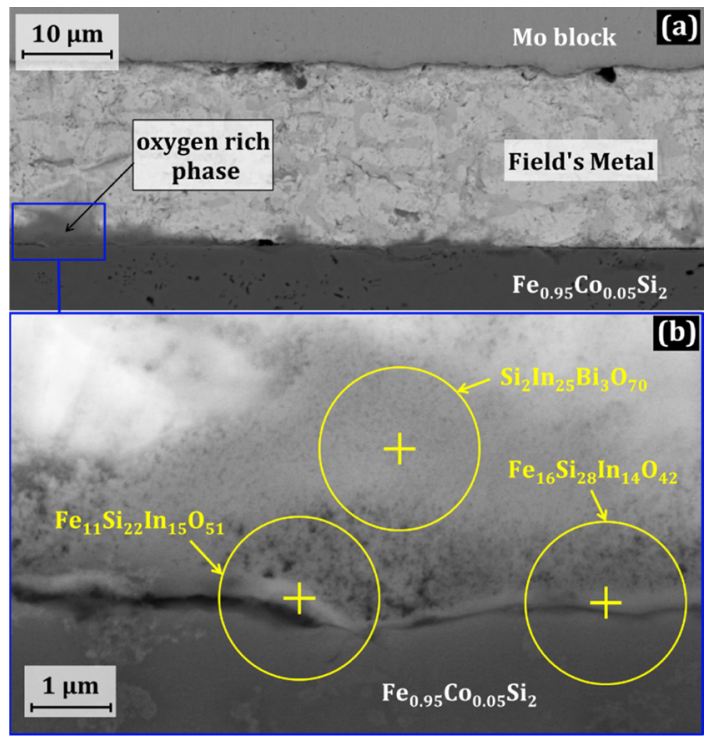

Figure 4. Angle-selective backscatter micrographs of the scheme 3 contact area cross section close to the envelope surface after a first temperature cycle (Figure 3). (a) Overview of the contact. (b) Zoom on an oxygen-rich phase area located on the sample contact surface. Yellow circles represent the spatial resolution of the EDX for the performed point scans. The labelled element ratios represent the at. \% values given by the EDX.

residual oxygen contained in the solder was detected close to the block's contact surface, whereas more detailed analysis did not reveal the formation of oxides on the block's side. The coexistence of the oxide phases only near $\mathrm{FeSi}_{2}$ strengthens the interpretation that oxygen contained in the solder predominantly reacts with silicon of the sample to form $\mathrm{SiO}_{2}$ on its surface. This is because the standard free energy of formation of $\mathrm{SiO}_{2}\left(-750 \mathrm{~kJ} / \mathrm{mol} \text { at } 370{ }^{\circ} \mathrm{C}\right)^{28}$ is much lower than the ones of $\mathrm{MoO}_{2}\left(-450 \mathrm{~kJ} / \mathrm{mol}\right.$ at $\left.370{ }^{\circ} \mathrm{C}\right)$ and $\mathrm{In}_{2} \mathrm{O}_{3}$ $\left(-460 \mathrm{~kJ} / \mathrm{mol}\right.$ at $\left.370{ }^{\circ} \mathrm{C}\right) .{ }^{29}$ This suggests the formation of a very thin glass or mixed oxide layer on the sample/contact interface. Figure 4 reveals that the oxygen-rich phase only contains oxide in the solder, assumed as $\operatorname{In}_{2} \mathrm{O}_{3}$, whereas no oxidation of the sample was clearly observed. The oxygen contents given in Figure 4 are only qualitatively relevant since the EDX detector did not allow a quantitative analysis of oxygen. There are most likely complex mixed stoichiometries existing among the solder elements. Due to the spatial resolution of the EDX system $(\sim 2 \mu \mathrm{m})$, it was not possible to confirm the assumed very thin oxide layers on the sample.

As stated previously, we consider that the oxygen content of the solder is the main instigator of the oxide formation on the $\mathrm{FeSi}_{2}$ contact surface. Nevertheless, we cannot ignore the small amount of oxygen that was detected in the $\mathrm{FeSi}_{2}$ samples. As mentioned in the Materials section, the sintered $\mathrm{FeSi}_{2}$ samples had a density lower than the theoretical one. Since diffusion processes are generally faster along grain boundaries than through the bulk of the crystallites, it seems reasonable to consider that the oxygen contained in the $\mathrm{FeSi}_{2}$ could migrate along the grain boundaries to the contact surface. Strictly, we cannot ignore that oxygen contained in the TE sample might be transferred to the contact and affect the contact properties; nevertheless, we assume that the impact must be minor as no oxygen was detected in the $\mathrm{FeSi}_{2}$ bulk by EDX, whereas more than 20 at. \% of oxygen was constantly detected in the solder. Benamati et al. showed that liquid $\mathrm{Bi}-\mathrm{Pb}$ solder saturated with oxygen was the source of surface oxidation of plunged steels from $300{ }^{\circ} \mathrm{C}$ on. ${ }^{30} \mathrm{All}$ in all, this tends to indicate that the sample surface oxidation was mainly caused by the oxygen contained in the solder.

Arima et al. ${ }^{31}$ deposited a thin $\mathrm{FeSi}_{2}$ layer to use as an oxidation barrier on top of pure silicon. This layer was kept under dry air at $900{ }^{\circ} \mathrm{C}$. The oxidation of the silicon surface without protection was continuously progressing and governed by the oxygen diffusion throughout the $\mathrm{SiO}_{2}$ layer that formed on the surface. In contrast, the silicon diffusion through the silicide layer to the outer surface dominates the growth of the silica layer on top of the $\mathrm{FeSi}_{2}$ barrier. Nanko et al. ${ }^{18}$ studied more specifically the oxidation behavior of the cobalt-doped $\mathrm{FeSi}_{2}$ at $800{ }^{\circ} \mathrm{C}$ in air. They found out that a $160 \mathrm{~nm}$ thick amorphous $\mathrm{SiO}_{2}$ layer was formed on the $\mathrm{FeSi}_{2}$ surface after 7 days. The growth of the oxide layer obeys a parabolic law (oxide growth is fast at the beginning and slows down with time) and depends on the annealing temperature. Nanko also observed the formation of the $\mathrm{FeSi}$ phase below the oxide layer. The consumption of silicon from the $\mathrm{FeSi}_{2}$, leading to the formation of $\mathrm{SiO}_{2}$, involved the following reaction: $\mathrm{FeSi}_{2}+\mathrm{O}_{2}=\mathrm{FeSi}+$ $\mathrm{SiO}_{2}$. Experiments have shown that after $2 \mathrm{~h}$ at $900{ }^{\circ} \mathrm{C}$, the silica layer grew to a thickness of about $80 \mathrm{~nm}^{31}$ and 7 days at $800^{\circ} \mathrm{C}$ led to a $160 \mathrm{~nm}$ thick oxide. ${ }^{18}$ Since experiments in the present study have been performed at a maximum temperature of 580 ${ }^{\circ} \mathrm{C}$ with $1 \mathrm{~h}$ holding time under vacuum, the thickness of an oxide layer formed on our $\mathrm{FeSi}_{2}$ sample should be below the values reported by Arima and Nanko, hence below the spatial resolution of the SEM/EDX investigation. Another study on $\mathrm{FeSi}_{2}$ deposition on a silicon substrate proved the formation of a self-passivation $\mathrm{SiO}_{2}$ layer on $\mathrm{FeSi}_{2}$ after a month in a desiccator under a dry air atmosphere. ${ }^{32}$ In addition, $\mathrm{FeSi}_{2}$ has also been reported as an efficient oxidation protection layer for magnesium silicide up to $600{ }^{\circ} \mathrm{C} .^{33}$

To evaluate the assumption of a silica layer formation on the sample contact surfaces in our study, the sample of scheme 2 was detached from the blocks after measurement on a hot plate set at $70{ }^{\circ} \mathrm{C}$. This is why, due to the convection in the liquified solder, the observed morphology of the solder is not representative of 
the one before removal. On the other hand, if a silicon oxide layer was formed during the temperature cycle, it would not be affected by the disassembling process. Nevertheless, a thin silicon oxide layer could have been damaged by the cut across the sample and the polishing steps for SEM/EDX investigation. In the resulting micrographs of Figure 5, a delamination between

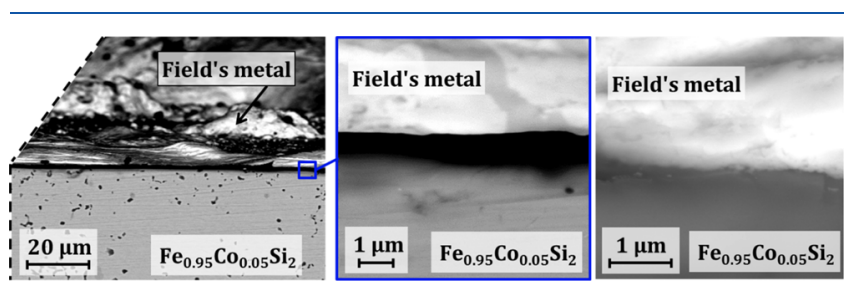

Figure 5. Angle-selective backscatter micrographs of the inner cross section of the sample/contact area of scheme 2 after the temperature cycle. A solder layer remained on the sample contact surface after sample detachment at $70{ }^{\circ} \mathrm{C}$. The contact between solder and sample alternates between direct contacts (right) and gaps (left).

the solder and the sample is observed at some locations. The same observation can be made in the right part of the sample's contact surface in the top micrograph of Figure 4. No oxide layer could be identified by EDX in the limits of its resolution. During the pre-soldering process, the initial oxide layer increasing the surface energy of the sample was only partially removed. During the measurement, the silicon oxide layer could be reformed on the overall sample contact surface due to the elevated temperature and the oxygen from the solder. The sample's surface energy, decreased by the oxide layer formation, reduced the wetting of the solder on the sample contact surface. This led to a delamination of solder and sample and increased the contact resistance significantly. As shown in Figure 6, an area of the same

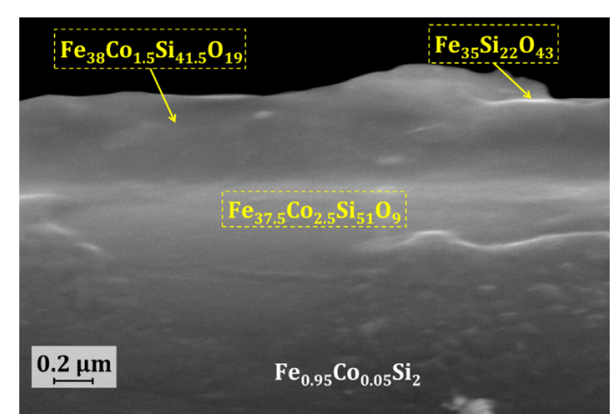

Figure 6. Secondary electron micrograph of the inner cross section of the sample contact surface of scheme 2 after the temperature cycle. The selected area was locally solder-free after dismounting. Labelled stoichiometries in the yellow dash frames correspond to integrated values obtained in EDX point scans over larger areas due to spatial resolution of the detector.

sample without remaining solder revealed the presence of $\mathrm{Fe}$ rich silicide phases at the contact surface combined with the significant oxygen content which could be attributed to the assumed silica layer and/or the formation of $\mathrm{Fe}-\mathrm{Si}$ oxide such as $\mathrm{Fe}_{2} \mathrm{SiO}_{4}$ or $\mathrm{FeSiO}_{3}$. The ratios given in the yellow dash frames (Figure 6) correspond to the atomic percentage values measured by the EDX and give only qualitative information, especially for the oxygen content.

During the holding period, under contact resistance measurement, scheme 1 (Figure 3) shows almost constant values, tending to indicate that the oxidation reaction dominating the degradation mechanism was stabilized around $540{ }^{\circ} \mathrm{C}$. At the holding temperature of 490 and $580^{\circ} \mathrm{C}$, respectively, the contact resistance of schemes 2 and 3 (Figure 3), continuously increased, indicating that the oxidation on the sample's surface was still in progress. Despite higher holding temperature, scheme 3 did not reach the stabilization status observed for scheme 1 . The difference between the surfaces' pre-treatments, performed on samples of schemes 1 and 3 , is assumed to be the origin of the disparity. While the inherent sample oxide layer of scheme 3 was totally removed by grinding before assembly, the sample superficial oxide of scheme 1 was only partially removed by the tip during the solder pre-soldering process, cf. Contacting method section. Therefore, the sample surface oxidation in scheme 3 required more time to stabilize even at higher temperature.

Regarding the formation enthalpies, it is likely that $\mathrm{SiO}_{2}$ is preferably formed rather than $\mathrm{FeSi}(-31.8 \mathrm{~kJ} / \mathrm{mol})$ or $\mathrm{FeSi}_{2}$ $(-24.3 \mathrm{~kJ} / \mathrm{mol}){ }^{34}$ hence oxygen should be able to take some silicon from $\mathrm{FeSi}_{2}$ to form $\mathrm{SiO}_{2}$ on the sample's contact surface. Starting from $415{ }^{\circ} \mathrm{C}$, the oxygen first reacts with the silicon of the $\mathrm{FeSi}_{2}$ which led to the formation of a silica layer on a thin $\mathrm{FeSi}$ and/or Fe-rich silicide layer, as assumed in Figure 6. Arima $^{31}$ mentioned that although oxygen was not diffusing through $\mathrm{FeSi}_{2}$, oxygen diffusion through $\mathrm{SiO}_{2}$ was important at $900{ }^{\circ} \mathrm{C}$. No information was available about $\mathrm{SiO}_{2}$ as a diffusion barrier for oxygen in the temperature range of our experiments. Two hypotheses could therefore explain the stabilization process observed in scheme 1 .

(1) Since the $\mathrm{SiO}_{2}$ 's growth obeys a parabolic law, the first nanometers formation should be fast and then oxide growth should slow down with time. If oxygen diffusion through the formed $\mathrm{SiO}_{2}$ is low in our temperature range, we could expect that the silica layer grows continuously until a thickness limit from which the oxide growth would be almost stabilized.

(2) If we assume a high oxygen diffusivity through the formed $\mathrm{SiO}_{2}$, the oxygen would be able to react with the Fe-rich silicide sublayer to form $\mathrm{FeSiO}_{3}{ }^{35}$ and/or $\mathrm{Fe}_{2} \mathrm{SiO}_{4}{ }^{36}$ that are dense enough to hinder the diffusion of oxygen to the $\mathrm{FeSi}_{2}$. The growth of the oxide layers would slow down, leading to a stabilization of the contact status same as for scheme 1 . Leveneur et al. ${ }^{37}$ studied the behavior of iron nanoparticles dissolved in $\mathrm{SiO}_{2}$ under beam electron annealing at $1000{ }^{\circ} \mathrm{C}$. The study revealed the formation of iron nanoclusters surrounded by a nanometer thick $\mathrm{Fe}-\mathrm{Si}$ oxide layer which protects iron from further oxidation. TEM analysis revealed a stoichiometry of $\mathrm{Fe}_{14} \mathrm{Si}_{19} \mathrm{O}_{67}$ for the $\mathrm{Fe}-\mathrm{Si}$ oxide. This study strengthens the hypothesis (2) involving the formation of a protective $\mathrm{Fe}-\mathrm{Si}$ oxide layer between the formed $\mathrm{SiO}_{2}$ and the $\mathrm{FeSi}_{2}$ sample for the higher temperature range in our experiments.

The obtained cooling curves have distinctive values due to different progress of degradation during heating and holding. The lack of any substantial reduction trends for the contact resistance during cooling indicates that the degradation mechanisms, which occur during heating, are not reversible. The final electrical contact resistance values, as shown in Figure 3 , are far above the threshold of $10 \%$ of the sample's resistance.

To separate the impact of the block and sample contact surfaces on the contact resistance, the scheme 2 sample was gently dismantled on a hot plate at $70{ }^{\circ} \mathrm{C}$ after the CoRIS measurement (Figure 3). The blocks were immediately soldered 
to each other with the remaining solder, spread on the contact surfaces. The specific contact resistance was newly measured at room temperature in the CoRIS, and a value of $40 \mu \Omega \cdot \mathrm{cm}^{2}$ is obtained, far below the final value after the temperature cycle. This confirms that the block/solder interface is hardly contributing to the high contact resistance and the observed evolution during cycling. Subsequently, the blocks were once again gently detached, and the former sample was reinstalled between the blocks with the remaining solder still spread on the different contact surfaces. The specific contact resistance at room temperature was newly measured in the CoRIS, and the obtained value was about $1500 \mu \Omega \cdot \mathrm{cm}^{2}$. This matches the room temperature value of the scheme 2 , obtained at the end of the temperature cycle in Figure 3. As a result, the experiment tends to confirm that the $\mathrm{FeSi}_{2}$ contact surface is the location of the strong increase of the contact resistance observed in the temperature-cycled schemes.

A fourth scheme was measured to analyze the behavior of the specific contact resistance below $415^{\circ} \mathrm{C}$, technically before the phase 4 starts (see Figure 7 ). Scheme 4 was prepared identically

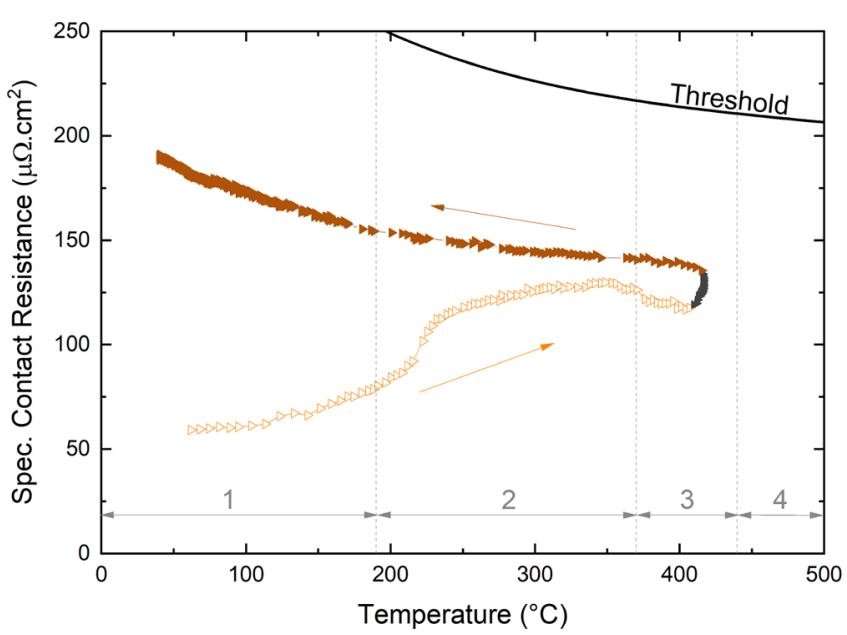

Figure 7. Specific contact resistance measurement on scheme 4. The four temperature phases of the contact resistance behavior during heating are indicated. The gray symbols represent the holding period. The threshold line gives the benchmark for CTEM measurement suitability at $10 \%$ of a typical sample resistance.

to scheme 3 with renewed materials. During the heating period, the specific contact resistance of scheme 4 shows the same trend as for schemes 2 and 3 in Figure 3. A 20 min holding period was intended at $410{ }^{\circ} \mathrm{C}$, but the temperature reached $415^{\circ} \mathrm{C}$ due to the inertia of the system during heating. The contact resistance increases as phase 4 starts from $410{ }^{\circ} \mathrm{C}$ at the beginning of the holding period. The monitored specific contact resistance increases at a rate of $43 \mu \Omega \cdot \mathrm{cm}^{2} / \mathrm{h}$ (see holding period in Figure 7). In comparison, the $1 \mathrm{~h}$ holding period for scheme 2 at $490{ }^{\circ} \mathrm{C}$ and scheme 3 at $580{ }^{\circ} \mathrm{C}$ showed degradation rates of 564 and $3200 \mu \Omega \cdot \mathrm{cm}^{2} / \mathrm{h}$, respectively. Therefore, the electrical contact degradation is accelerated with increasing temperature until the dominating degradation mechanism saturates, as for scheme 1 in Figure 3. Scheme 4 reveals that the oxidation mechanism observed in schemes 1,2 , and 3 is already effective at $410{ }^{\circ} \mathrm{C}$ and intensifies at higher temperature. The slow degradation of the electrical contact makes the developed contact suitable for short duration exposure up to $415{ }^{\circ} \mathrm{C}$.

\section{CONCLUSIONS}

In this study, we tested the electrical specific resistance and the temperature-bound degradation of the contact molybdenum$\mathrm{FM}-\mathrm{Fe}_{0.95} \mathrm{Co}_{0.05} \mathrm{Si}_{2}$. The contact fulfills the criterion of easy disassembly after cycling since, after measurement, the solder still melts at $62{ }^{\circ} \mathrm{C}$ and allows an easy sample extraction. Despite the fact that high vacuum conditions were kept during temperature cycling, oxygen was detected in the contact area, especially in the solder. The said oxygen caused a series of reactions in the system. In the first phase of heating, the formation of dross, mainly $\operatorname{In}_{2} \mathrm{O}_{3}$, is enhanced on the solder's surface. At higher temperatures, the $\operatorname{In}_{2} \mathrm{O}_{3}$ compound decomposed into volatile $\mathrm{In}_{2} \mathrm{O}$ at $370{ }^{\circ} \mathrm{C}$. In direct contact to the $\mathrm{FeSi}_{2}$ sample, the oxygen forms a thin insulating silica layer on the sample contact surface starting between 410 and $440{ }^{\circ} \mathrm{C}$. The formation of $\mathrm{SiO}_{2}$ caused a thin layer of $\mathrm{FeSi}$ on the $\mathrm{FeSi}_{2}$ sample and a possible reaction of oxygen to $\mathrm{Fe}-\mathrm{Si}$ oxides. The insulating mixed oxide layer formed on the $\mathrm{FeSi}_{2}$ sample promoted a strong increase of the electrical contact resistance which exceeded the fixed threshold, that is, $10 \%$ of the sample's resistance. However, we proved that the contact resistance remained below the threshold below $415{ }^{\circ} \mathrm{C}$ as long as the sample surface is carefully polished before mounting to the sample holder. In addition, besides the superficial oxidation, no other chemical reactions were observed in the contact area which enables to reuse the sample and blocks for other tests. As a result, the developed contact seems applicable for the CTEM sample mounting up to $415{ }^{\circ} \mathrm{C}$ for short duration measurements. The deposition of an anti-oxidation layer could help to prevent the formation of insulating oxides on the $\mathrm{FeSi}_{2}$ sample, expanding the temperature range for CTEM measurements.

\section{AUTHOR INFORMATION}

\section{Corresponding Authors}

Antoine Micallef - Institute of Materials Research, German Aerospace Center (DLR), D-51170 Cologne, Germany; (1) orcid.org/0000-0003-4265-9236;

Email: antoine.micallef@dlr.de

Christian Stiewe - Institute of Materials Research, German Aerospace Center (DLR), D-51170 Cologne, Germany; Email: christian.stiewe@dlr.de

\section{Authors}

Gregor Oppitz - Institute of Materials Research, German Aerospace Center (DLR), D-51170 Cologne, Germany

Eckhard Müller - Institute of Materials Research, German Aerospace Center (DLR), D-51170 Cologne, Germany; Institute for Inorganic and Analytical Chemistry, Justus Liebig University Giessen, D-35392 Giessen, Germany

Complete contact information is available at:

https://pubs.acs.org/10.1021/acsaelm.0c01020

\section{Author Contributions}

The manuscript was written by A.M. through contributions of all authors. All authors have given approval to the final version of the manuscript. A.M. and C.S. contributed equally to this work. G.O. developed the computer program allowing data monitoring. E.M. participated in the result analysis and supervised the overall content production.

\section{Notes}

The authors declare no competing financial interest. 


\section{ACKNOWLEDGMENTS}

A.M. would like to thank the German Academic Exchange Service (DAAD) for the endorsement. We also want to thank AixACCT Systems $\mathrm{GmbH}$ for their cooperation in this project, Thomas Coutts for his diligent proofreading of this paper, and all our colleagues at DLR for their daily help.

\section{REFERENCES}

(1) Kolb, H.; Dasgupta, T.; Zabrocki, K.; Mueller, E.; De Boor, J. Simultaneous measurement of all thermoelectric properties of bulk materials in the temperature range 300-600 K. Rev. Sci. Instrum. 2015, $86,073901$.

(2) Ioffe, A.; Ioffe, A. Measurement of the thermal conductivity of semiconductors in the vicinity of room temperature. Soviet Phys. Tech. Phys. 1958, 3, 2163-2168.

(3) Stecker, K.; Teubner, M. Untersuchungen verschiedener methoden der wärmeleitsmessungen an Halbleitern. Wiss. Z.-Martin-LutherUniv. Halle-Wittenberg, Math.-Naturwiss. Reihe XVI 1967, 67, 1.

(4) Müller, E. Bandstruktur und ladungsträgerstreuung in p-leitenden (Bi1-xSbx)2Te3-mischkristallen. Fortschr.-Ber. VDI 1998, 19, 1-236.

(5) Koh, A.; Hwang, W.; Zavalij, P. Y.; Chun, S.; Slipher, G.; Mrozek, R. Solidification and melting phase change behavior of eutectic galliumindium-tin. Materialia 2019, 8, 100512.

(6) Beltrán-Pitarch, B.; Prado-Gonjal, J.; Powell, A. V.; Ziolkowski, P.; García-Cañadas, J. Thermal conductivity, electrical resistivity, and dimensionless figure of merit $(\mathrm{ZT})$ determination of thermoelectric materials by impedance spectroscopy up to $250^{\circ} \mathrm{C}$. J. Appl. Phys. 2018, 124, 025105

(7) Beltrán-Pitarch, B.; Prado-Gonjal, J. s.; Powell, A. V.; MartínezJulián, F.; García-Cañadas, J. Complete Characterization of Thermoelectric Materials by Impedance Spectroscopy. J. Phys. Chem. C 2019, 123, 12608-12613.

(8) Lenz, E.; Edler, F.; Ziolkowski, P. Traceable thermoelectric measurements of Seebeck coefficients in the temperature range from $300 \mathrm{~K}$ to $900 \mathrm{~K}$. Int. J. Thermophys. 2013, 34, 1975-1981.

(9) PTB. RN/SB-FeSi2-2015. Referenz-Normal für Seebeck-Koeffizienten, Eisendisilizid, FeSi2, Temperaturbereich 300 K-800 K; PhysikalischTechnische Bundesanstalt (PTB): Braunschweig und Berlin, Germany, September 4, 2015; pp 1-6.

(10) Schackenberg, K.; Müller, E.; Schilz, J.; Ernst, H.; Kaysser, W. A. Carrier density behaviour during ageing of doped plasma spray formed iron disilicide. Seventeenth International Conference on Thermoelectrics; IEEE: Nagoya, Japan, 1998; pp 422-425.

(11) Chen, H. Y.; Zhao, X. B.; Zhu, T. J.; Jiang, J. Z.; Stiewe, C.; Lathe, C.; Mueller, E. In situ energy dispersive X-ray diffraction study of iron disilicide thermoelectric materials. J. Phys. Chem. Solids 2008, 69, 2013-2018.

(12) Mousavi, T.; Aksoy, C.; Grovenor, C. R. M.; Speller, S. C. Microstructure and superconducting properties of $\mathrm{Sn}$-In and $\mathrm{Sn}$-In-Bi alloys as $\mathrm{Pb}$-free superconducting solders. Supercond. Sci. Technol. 2015, 29, 015012 .

(13) Kamal, M.; El-Bediwi, A.-B.; Shalaby, R.; Younus, M. A study of eutectic indium-bismuth and indium-bismuth-tin Field's metal rapidly solidified from melt. J. Adv. Phys. 2015, 7, 1404-1413.

(14) Okamoto, H. Fe-In (Iron-Indium). In Phase Diagrams of Indium Alloys and Their Engineering Applications; White, C. E. T., Okamoto, H., Eds.; ASM International: Materials Park, OH, US, 1992; Vol. 8, pp 106-108.

(15) Okamoto, H. In-Mo (Indium-Molybdenum). In Phase Diagrams of Indium Alloys and Their Engineering Applications; White, C. E. T., Okamoto, H., Eds.; ASM International: Materials Park, OH, US, 1992; Vol. 8, pp 173-174.

(16) Olesinski, R. W.; Kanani, N.; Abbaschian, G. J. In-Si (IndiumSilicium). In Phase Diagrams of Indium Alloys and Their Engineering Applications; White, C. E. T., Okamoto, H., Eds.; ASM International: Materials Park, OH, US, 1992; Vol. 8, pp 250-252.
(17) Stecker, K.; Süssmann, H.; Eichler, W.; Heiliger, W.; Stordeur, M. Zur Physik thermoelektrischer Halbleiterstoffe auf der Basis von Bi2Te3-Sb2Te3. Wiss. Z. Halle XXVII'78 1978, 5, 5-63.

(18) Nanko, M.; Chang, S. H.; Matsumaru, K.; Ishizaki, K.; Takeda, M. Isothermal oxidation of sintered $\beta-\mathrm{FeSi} 2$ in air. Materials Science Forum; Trans Tech Publications, 2006; Vol. 522, pp 641-648.

(19) Eustathopoulos, N.; Nicholas, M. G.; Drevet, B. Chapter 1 Fundamental equations of wetting. In Wettability at High Temperatures; Cahn, R. W., Ed.; Elsevier Science Ltd.: Oxford, 1999; Vol. 3, pp 1-53. (20) Ricci, E.; Arato, E.; Passerone, A.; Costa, P. Oxygen tensioactivity on liquid-metal drops. Adv. Colloid Interface Sci. 2005, 117, 15-32.

(21) Fiori, L.; Ricci, E.; Arato, E.; Costa, P. Dynamic surface tension measurements on a molten metal-oxygen system: The behaviour of the temperature coefficient of the surface tension of molten tin. J. Mater. Sci. 2005, 40, 2155-2159.

(22) Jeon, A.-J.; Kim, S.-J.; Lee, S.-H.; Kang, C.-Y. Effect of indium content on the melting point, dross, and oxidation characteristics of Sn2Ag-3Bi-xIn solders. J. Electron. Packag. 2013, 135, 021006.

(23) Ricci, E.; Lanata, T.; Giuranno, D.; Arato, E. The effective oxidation pressure of indium-oxygen system. J. Mater. Sci. 2008, 43, 2971-2977.

(24) Lundberg, N.; Erlesand, U.; Östling, M. Oxidation of Semiconducting Iron Disilicide ( $\beta$-FeSi2). MRS Online Proceedings Library Archive; Cambridge University Press, 1992, p 260.

(25) Jenko, M.; Erjavec, B.; Praček, B. AES studies of surface phenomena on liquid indium solder. Vacuum 1990, 40, 77-79.

(26) Führ, G.; Genser, C.; Nachod, G.; Pohland, E.; Seuferling, F.; Thalinger, M.; Zeise, H. Indium und Sauerstoff. Indium; Springer, 1969; pp 64-70.

(27) Boggs, W. E.; Trozzo, P. S.; Pellissier, G. E. The Oxidation of Tin Ii. The Morphology and Mode of Growth of Oxide Films on Pure Tin. J. Electrochem. Soc. 1961, 108, 13-24.

(28) Birks, N.; Meier, G.; Pettit, F. Thermodynamic fundamentals. Introduction to the High Temperature Oxidation of Metals, 2nd ed.; Cambridge University Press: Cambridge, 2006; pp 16-38.

(29) Kleykamp, H. The chemical state of the fission products in oxide fuels. J. Nucl. Mater. 1985, 131, 221-246.

(30) Benamati, G.; Fazio, C.; Piankova, H.; Rusanov, A. Temperature effect on the corrosion mechanism of austenitic and martensitic steels in lead-bismuth. J. Nucl. Mater. 2002, 301, 23-27.

(31) Arima, M.; Fuchi, M.; Narumi, K.; Maeda, Y., Analysis of oxidation behavior in nanocrystal $\beta$ - $\mathrm{FeSi} / \mathrm{Si}$ composites by rutherford backscattering spectrometry and computation of diffusion flux. JJAP Conference Proceedings; The Japan Society of Applied Physics, 2016; Vol. 5, pp 0111051-0111055.

(32) Saito, T.; Yamamoto, H.; Sasase, M.; Nakanoya, T.; Yamaguchi, K.; Haraguchi, M.; Hojou, K. Surface chemical states and oxidation resistivity of 'ecologically friendly' semiconductor $(\beta$-FeSi2 $)$ thin films. Thin Solid Films 2002, 415, 138-142.

(33) Tani, J.-i.; Takahashi, M.; Kido, H. Thermoelectric properties and oxidation behaviour of Magnesium Silicide. IOP Conference Series: Materials Science and Engineering; IOP Publishing, 2011; p 142013.

(34) Fries, S. G.; Jantzen, T. Compilation of "CALPHAD" formation enthalpy data: Binary intermetallic compounds in the COST 507 Gibbsian database. Thermochim. Acta 1998, 314, 23-33.

(35) Stackhouse, S.; Brodholt, J. P.; Price, G. D. Elastic anisotropy of $\mathrm{FeSiO} 3$ end-members of the perovskite and post-perovskite phases. Geophys. Res. Lett. 2006, 33, L013041-L013044.

(36) Takei, H. Growth of fayalite ( $\mathrm{Fe} 2 \mathrm{SiO} 4)$ single crystals by the floating-zone method. J. Cryst. Growth 1978, 43, 463-468.

(37) Leveneur, J.; Sanchez, D. F.; Kennedy, J.; Grande, P. L.; Williams, G. V. M.; Metson, J. B.; Cowie, B. C. C. Iron-based bimagnetic core/ shell nanostructures in SiO 2: a TEM, MEIS, and energy-resolved XPS analysis. J. Nanopart. Res. 2012, 14, 1149. 